\title{
PENGEMBANGAN PENGELOLAAN SAMPAH PERKOTAAN DENGAN POLA PEMANFAATAN SAMPAH BERBASIS MASYARAKAT DI KABUPATEN TANAH DATAR
}

\section{DEVELOPMENT OF COMMUNITY-BASED MUNICIPAL SOLID WASTE MANAGEMENT IN TANAH DATAR REGENCY}

\author{
Slamet Raharjo, Taufiq Ihsan, Tiara Wahyuni \\ Jurusan Teknik Lingkungan, Fakultas Teknik, Universitas Andalas \\ Kampus Limau Manis, Padang, Telp. (0751)72497, Fax. (0751)72564 \\ Email: sraharjo@ft.unand.ac.id
}

\begin{abstract}
ABSTRAK
Masalah persampahan di Kabupaten Tanah Datar, Sumatera Barat belum mendapat perhatian yang serius dari pemerintah. Hal ini dapat dilihat dari rendahnya praktik pemanfaatan sampah dan tingkat pelayanan yaitu 3,71\% dengan satuan timbulan 3,646 l/orang/hari. Berdasarkan pengolahan data hasil kuisioner, dapat disimpulkan bahwa minimnya jumlah sarana dan prasarana serta partisipasi masyarakat juga menjadi faktor yang menyebabkan sampah belum dapat ditangani dengan baik. Upaya yang dapat dilakukan untuk mengatasi permasalahan ini adalah dengan melakukan studi pengembangan pengelolaan sampah di Kabupaten Tanah Datar selama 20 tahun yang dibagi atas tiga tahap yaitu Tahap I (2016-2020), Tahap II (2021-2025) dan Tahap III (2026-2035) Perencanaan meliputi pengembangan tingkat pelayanan serta aspek teknis dan non teknis persampahan. Perencanaan daerah pelayanan dibagi atas lima zona yaitu Zona A, B, C, D dan E. Peningkatan partisipasi masyarakat dapat dilakukan dengan pembangunan TPS $3 R$ yang berbasis masyarakat dengan sistem Bank Sampah. Pengolahan yang dilakukan berupa pengomposan untuk sampah basah dengan metode Takakura Susun dan Rotary Kiln serta daur ulang untuk sampah kering. Penerapan daur ulang di Zona A direncanakan mencapai target $20 \%$ di akhir periode desain karena Zona A merupakan zona prioritas. Penerapan daur ulang ini bertujuan untuk meminimalisir jumlah sampah yang masuk ke TPA dan memperpanjang umur pakai TPA.
\end{abstract}

Kata Kunci: Pengelolaan Sampah, Aspek Teknis, Aspek Non Teknis, 3R, Tanah Datar

\begin{abstract}
There was a lack attention regarding municipal solid waste management in Tanah Datar Regency, West Sumatera. Current condition shows that the achievement of waste management services is only $3.71 \%$ of the total waste generation, with a generation unit of $3.646 \mathrm{l} / \mathrm{cap} /$ day. Questionnaires results suggest that the limited facilities, infrastructures and community participations result in low achievement of the waste management service. Developing solid waste management in Tanah Datar Regency for 20 years would become a solution for this case. This program is divided in three stages: Stage I (2016-2020), Stage II (2021-2025) and Stage III (2026-2035). Planning program covers development of service levels, technical and non technical aspects of solid waste. There are five zones for area development, Zone $A, B, C, D$ and $E$. Community participation can be developed by applying community-based TPS $3 R$ through Solid Waste Bank (SWB) system. Solid waste handling includes composting using Takakura Method and Rotary Kiln, and recycling for dry waste. Achievement of recycling in Zone A would reach $20 \%$ in the end of design period since Zone $A$ is priority. This application aims to minimize the amount of waste entering the municipal landfill and extend its lifetime.
\end{abstract}

Keyword: Solid waste Management, Technical Aspects, Non-Technical Aspects, 3R, Tanah Datar 


\section{PENDAHULUAN}

\section{Latar Belakang}

Sampah merupakan sebuah permasalahan yang sampai saat ini belum dapat ditangani dengan baik di berbagai kota di Indonesia. Seiring dengan pesatnya laju pertumbuhan penduduk dan meningkatnya kegiatan industri menyebabkan produksi sampah semakin meningkat, baik itu sampah domestik maupun sampah non domestik. Jika peningkatan produksi sampah di Indonesia tidak diiringi dengan pengelolaan yang baik, maka akan menimbulkan masalah yang cukup serius bagi suatu perkotaan. Sistem pengelolaan persampahan di suatu kota sangat dibutuhkan untuk mengurangi dampak negatif yang dapat merusak lingkungan dan membahayakan kesehatan masyarakat.

Apabila sampah di suatu perkotaan tidak dapat dikelola dengan baik maka akan menjadi beban dan menimbulkan masalah yang besar, namun sebaliknya jika dikelola dengan benar, maka akan menjadi aset dan dapat bermanfaat bagi pemerintah maupun masyarakat. Permasalahan persampahan harus diantisipasi agar tidak menimbulkan bahaya pencemaran lingkungan yang semakin parah di kemudian hari, maka perlu dikembangkan sistem pengelolaan sampah dengan konsep 3R (Reduce, Reuse dan Recycle) sesuai dengan Undang-Undang (UU) No. 18 Tahun 2008 tentang Pengelolaan Persampahan.

Undang- undang ini mengatur tentang perubahan paradigma lama sistem pengelolaan sampah yaitu kumpul, angkut dan buang menjadi sistem pengelolaan sampah dengan paradigma baru dengan melakukan pengolahan di sumber atau di tempat pengolahan sampah berupa Tempat Pengolahan Sampah dengan metode $3 R$ atau yang dikenal dengan TPS $3 \mathrm{R}$ dan Tempat Pengolahan Sampah Terpadu (TPST). Pengolahan yang dilakukan akan mengurangi jumlah sampah yang akan di buang ke Tempat Pemrosesan Akhir (TPA) sehingga dapat mengurangi luas lahan urug yang diperlukan serta dapat menambah umur pakai TPA.

Oleh sebab itu, perlu dilakukan studi pengembangan pengelolaan sampah di Kabupaten Tanah Datar yang meliputi aspek teknis dan non teknis persampahan. Aspek teknis meliputi pewadahan, pengumpulan, pengangkutan, pengolahan dan pembuangan akhir, sedangkan aspek non teknis meliputi kelembagaan dan peraturan. Dengan dilakukannya studi pengembangan ini diharapkan dapat terciptanya lingkungan yang bersih dan ideal.

\section{Maksud}

Maksud dari perencanaan ini adalah merencanakan pengembangan sampah perkotaan di Kabupaten Tanah Datar dengan pola pemanfaatan sampah berbasis masyarakat.

\section{Tujuan}

Tujuan dari perencanaan ini adalah:

1. Mengevaluasi sistem pengelolaan sampah eksisting Kabupaten Tanah Datar;

2. Merencanakan skenario pengembangan daerah dan tingkat pelayanan serta target $3 R$ di Kabupaten Tanah Datar;

3. Merencanakan skenario pengelolaan sampah meliputi aspek teknis dengan pola pemanfaatan sampah;

4. Merencanakan program pengembangan pengelolaan persampahan dengan pola pemanfaatan sampah.

\section{METODOLOGI}

Perencanaan pengembangan berlokasi di Kabupaten Tanah Datar dengan luas $1.336 \mathrm{~km}^{2}$ dengan jumlah penduduk 343.882 jiwa (BPS, 2014). Berikut merupakan tahapan pengembangan:

\section{Studi Literatur}

Studi literatur, yaitu mencakup kegiatan pengumpulan literatur sebagai dasar dalam melakukan perencanaan pengelolaan persampahan Kabupaten Tanah Datar. Studi literatur berfungsi untuk memberikan informasi dan teori yang berkaitan dengan penelitian yang mengkaji tentang upaya terpadu dalam pengelolaan persampahan.

\section{Pengumpulan Data Primer}

Pengumpulan data primer dilakukan untuk memperoleh pendekatan mengenai pola persebaran penduduk dan pola penanganan sampah di kawasan Kabupaten Tanah Datar. Pengumpulan data ini dilakukan dengan teknik wawancara dengan pihak KLH dan penyebaran kuisioner.

\section{Pengumpulan Data Sekunder}

Pengumpulan data sekunder dilakukan dengan analisis dokumen yang bertujuan untuk memperoleh data-data mengenai data kependudukan, peta wilayah (luas wilayah, 
administrasi, topografi, tata guna lahan), data pengembangan wilayah (pengembangan fasilitas umum dan kawasan) Kabupaten Tanah Datar, data kelembagaan dan peraturan terkait pengelolaan persampahan Kabupaten Tanah Datar.

4. Identifikasi Permasalahan

Identifikasi masalah ini mengacu kepada beberapa peraturan yaitu Undang-Undang No 18 Tahun 2008 tentang Pengelolaan Sampah, Peraturan Menteri Pekerjaan Umum Republik Indonesia Nomor 03/PRT/M/2013 tentang Penyelenggaraan Prasarana dan Sarana Persampahan dalam Penanganan Sampah Rumah Tangga dan Sampah Sejenis Sampah Rumah Tangga serta Peraturan Menteri Pekerjaan Umum No. 21 Tahun 2006 tentang Kebijakan dan Strategi Nasional Pengembangan Sistem Pengelolaan Persampahan (KSNP-SPP).

\section{Perencanaan}

Periode perencanaan dilakukan selama 20 tahun yang dibagi atas 3 tahap yaitu:
a. Tahap I (2016-2020);
b. Tahap II (2021-2025);
c. Tahap III (2026-2035).

KONDISI EKSISTING PENGELOLAAN PERSAMPAHAN KABUPATEN TANAH DATAR

\section{Umum}

Sumber sampah di Kabupaten Tanah Datar berasal dari kegiatan domestik yang didominasi oleh sampah basah dan non domestik seperti pasar, perkantoran, jalan, fasilitas umum dan sebagainya. Menurut penelitian Zulva (2013) bahwa timbulan rata-rata Kabupaten Tanah Datar adalah 3,646 1/o/h. Secara umum sistem pengelolaan sampah Kabupaten Tanah Datar masih menerapkan sistem kumpul-angkut-buang.

Sistem pengumpulan berupa individual langsung dan komunal langsung, sarana yang digunakan berupa truk dengan kapasitas $8 \mathrm{~m}^{3}$, sampah yang dikumpulkan tercampur. Setelah dikumpulkan, sampah langsung dibuang ke TPA yang berlokasi di Bukit Sangkiang, dengan alat angkut berupa dump truck dan armroll truck. Sistem pembuangan masih berupa open dumping. Lebih jelasnya dapat dilihat pada Gambar 1.

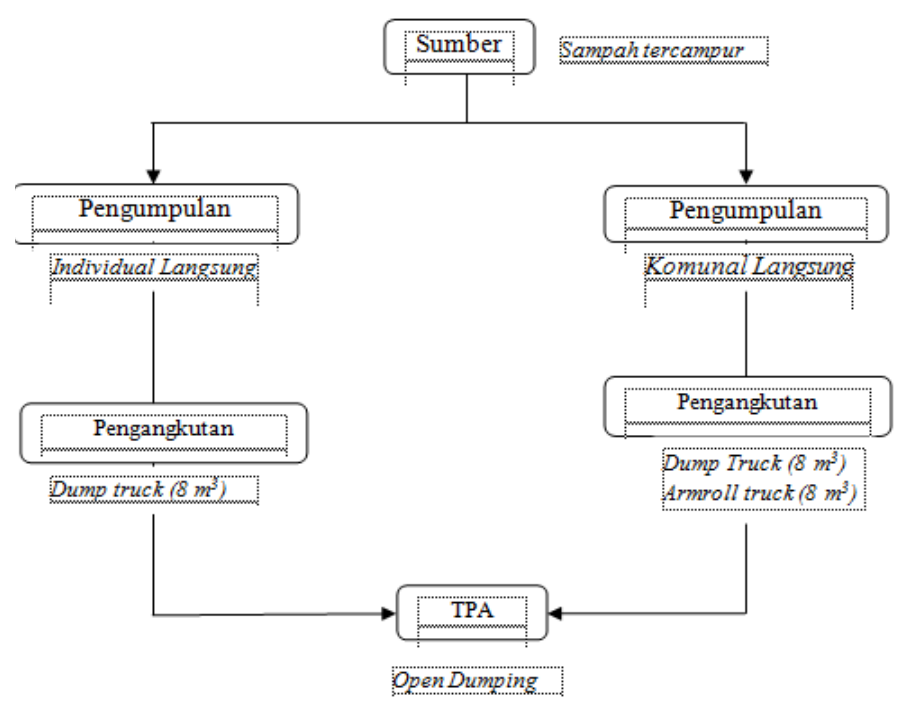

Gambar 1. Kondisi Eksisting Pengelolaan Sampah Pengolahan Sampah

Pemerintah Kabupaten Tanah Datar saat ini belum melaksanakan pengelolaan sampah 3R secara menyeluruh. Kecamatan yang memiliki bangunan fisik TPS 3R berbasis masyarakat yaitu Kecamatan Lima Kaum. Dimana kegiatan ini didukung dan dibiayai oleh pemerintah provinsi. Kegiatan yang dilakukan di TPS 3R ini meliputi pengomposan dan daur ulang. Kawasan yang dilayani oleh TPS 3R di Lima Kaum ini hanya Perumahan Koppas, Dobok yang memiliki sekitar 200 Kepala Keluarga (KK). Namun karena kurangnya partisipasi masyarakat dan dukungan dari pemerintah, sampai saat ini TPS $3 \mathrm{R}$ ini tidak beroperasi lagi.

Bangunan ini memiliki luas sekitar $100 \mathrm{~m}^{2}$ yang dilengkapi dengan alat pengomposan yaitu rotary kiln yang berkapasitas $3 \mathrm{~m}^{3}$ sebanyak lima buah. Sampah yang akan diolah berasal dari komplek perumahan yang dijemput dengan becak motor. Sampah yang dikumpulkan belum dipisah sehingga perlu dilakukan pemilahan di TPS 3R ini. Selain rotary kiln terdapat satu unit alat pencacah sampah yang berfungsi untuk mencacah sampah sebelum dikompos. 


\section{Analisis Permasalahan}

1. Timbulan Sampah

a. Jumlah penduduk yang tinggi menyebabkan jumlah sampah yang dihasilkan semakin tinggi;

b. Belum adanya kepedulian masyarakat sebagai penghasil sampah untuk mengurangi dan memanfaatkan sampah yang masih dapat digunakan;

c. Masyarakat cenderung menggunakan kemasan produk yang tidak dapat di daur ulang sehingga menambah jumlah timbulan sampah.

d. Masyarakat belum memilah sampah yang dihasilkan.

2. Tingkat dan daerah pelayanan

a. Belum adanya zonasi terhadap wilayah penghasil sampah sehingga mempersulit pengontrolan terhadap penanganan sampah;

b. Pelayanan belum mencakup seluruh daerah Kabupaten Tanah Datar. Berdasarkan Peraturan Menteri Pekerjaan Umum No. 21 Tahun 2006 pelayanan minimum suatu kabupaten atau kota adalah $60 \%$, namun setelah dilakukan perhitungan diperoleh tingkat pelayanan masih $3,71 \%$.

c. Sebanyak $92 \%$ daerah Kabupaten Tanah Datar belum terlayani oleh Dinas Kebersihan.Kabupaten.

\section{Aspek Teknis}

a. Pewadahan

- Wadah yang disediakan merupakan wadah bersekat yaitu organik dan anorganik, namun kenyataannya sampah yang ditampung masih sampah yang belum terpilah.

- Berdasarkan pengolahan hasil kuisioner didapatkan kesimpulan bahwa 89,47\% masyarakat menyatakan bahwa jumlah sarana pewadahan tidak memadai, dan 94,73\% masyarakat tidak menggunakan wadah terpilah.

b. Pengumpulan

Hasil kuisioner menunjukan bahwa $89,47 \%$ masyarakat mengatakan bahwa belum tercukupinya jumlah alat pengumpul sampah seperti gerobak sampah dan truk sampah dan juga keterbatasan petugas pengumpul yang menyebabkan jadwal pengumpulan tidak rutin, sehingga hanya $73,68 \%$ daerah pelayanan yang dilayani tidak berjalan dengan baik.

c. Pengangkutan

- Setelah dilakukan pengolahan data hasil kuisioner dapat disimpulkan, 73,68\% sampah belum terangkut ke TPA, hal ini disebabkan oleh terbatasnya jumlah armada alat angkut dan dana sehingga pengangkutan hanya dilakukan 1 kali dalam sehari dengan sampah yang diangkut $48,28 \mathrm{~m}^{3} /$ hari.

- Tidak adanya pengawasan terhadap pelaksanaan pengangkutan.

d. Sistem Pengolahan Sampah

Kurangnya partisipasi masyarakat dalam pengolahan persampahan. Dari hasil kuisioner diperoleh informasi bahwa hanya $36,84 \%$ masyarakat yang melakukan pengolahan sampah di sumber. Bangunan fisik 3R ini telah didukung oleh fasilitas yang ada namun tidak dimanfaatkan. Sistem pengomposan menggunakan rotary kiln untuk pengomposan, namun fasilitas yang ada tidak dimanfaatkan oleh masyarakat setempat.

e. Tempat Pemrosesan Akhir (TPA)

- Pengolahan yang dilakukan di TPA Bukit Sangkiang masih berupa open dumping;

- Fasilitas yang terdapat pada TPA Bukit Sangkiang ini dapat dikatakan minim sekali, berdasarkan kondisi eksistingnya fasilitas yang ada sebagai berikut:

$\checkmark$ Fasilitas umum terdiri dari jalan masuk dan kantor jaga.

$\checkmark$ Fasilitas perlindungan hanya lapisan kedap air dan daerah penyangga;

$\checkmark$ Fasilitas operasional berupa satu buah excavator dan dua bulldozer.

\section{Analisis Kebutuhan Pengembangan}

Berdasarkan permasalahan-permasalahan yang ada, kebutuhan pengembangan yang perlu ada diantaranya:

1. Timbulan

a. Melakukan studi tentang timbulan sampah secara berkala.

b. Melakukan sosialisasi untuk mengingatkan warga agar membuang sampah pada tempatnya dan melakukan pemilahan di sumber.

2. Tingkat dan Daerah Pelayanan 
a. Melakukan peningkatan tingkat pelayanan secara bertahap minimal $60 \%$.

b. Pembagian zonasi dalam perencanaan daerah pelayanan di Kabupaten Tanah Datar.

3. Pewadahan

a. Memberikan sosialisasi kepada masyarakat agar memilah sampah di sumber dan tidak membuang sampah sembarangan.

b. Memaksimalkan jumlah sarana pengumpul.

4. Penambahan jumlah sarana pengumpul dan memaksimalkan frekuensi pengumpulan sehingga seluruh sampah yang terlayani dapat dimaksimalkan.

5. Pengangkutan

a. Menambah jumlah alat angkut terutama armroll truck.

b. Menetapakan jadwal dan rute pengangkutan agar pengangkutan sampah lebih terstruktur

c. Memaksimalkan ritasi dan kapasitas kendaraan angkut.

6. Pengolahan Sampah

a. Melakukan sosialisasi tentang pengolahan sampah kepada masyarakat setempat.

b. Mengoperasikan kembali bangunan TPS 3R yang telah ada dengan melakukan pengolahan sampah seperti pengomposan dan daur ulang.

c. Menambah jumlah bangunan pengolahan sampah di nagari lain sesuai dengan target $3 R$ yang akan ditentukan, dengan dilakukan pengolahan sampah maka beban sampah yang masuk ke TPA akan berkurang.

7. Tempat Pemrosesan Akhir (TPA)

a. Mengubah sistem open dumping dengan sistem sanitary landfill pada TPA ini sesuai dengan Undang-undang No.18 Tahun 2008;

b. Menambah jumlah fasilitas dasar, penunjang, operasional dan perlindungan lingkungan.

\section{SKENARIO PENGEMBANGAN}

\section{Dasar-dasar Pengembangan}

a. Rencana Tata Ruang Wilayah (RTRW)

RTRW Kabupaten Tanah Datar (Perda Kabupaten Tanah Datar, 2012) digunakan sebagai acuan dalam menetapkan periode desain selama 20 tahun dan penetapan pengembangan daerah pelayanan sesuai dengan kawasan strategis yang ada di RTRW.

\section{b. Peraturan Menteri Pekerjaan Umum No. 21 Tahun 2006}

Berdasarkan peraturan ini maka tingkat pelayanan masing-masing zona harus mencapai minimal $60 \%$.

\section{c. Hasil Kuisioner}

Pembagian kuisioner dilakukan di Perumahan Koppas Dobok, Nagari Lima Kaum dengan jumlah responden sebanyak 19 responden. Adapun rekapitulasi hasil kuisioner dapat dilihat pada Tabel 1.

Tabel 1. Rekapitulasi Hasil Kuisioner

\begin{tabular}{clr}
\hline No & \multicolumn{1}{c}{ Aspek } & Persentase (\%) \\
\hline 1 & Pewadahan Terpilah & 5,27 \\
\hline 2 & Pengumpulan sampah oleh KLH & 10,53 \\
\hline 3 & Jumlah armada mencukupi & 0,00 \\
\hline 4 & Pengolahan & 36,84 \\
\hline
\end{tabular}

Berdasarkan hasil kuisioner di atas dapat diketahui bahwa masalah persampahan di Kabupaten Tanah Datar masih terkendala dengan minimnya partisipasi masyarakat dalam mengolah sampah. Selain itu juga jumlah armada persampahan yang tidak mencukupi untuk melayani semua sampah yang dihasilkan.

\section{d. Hasil Wawancara}

Setelah dilakukan wawancara dengan pihak KLH dapat disimpulkan bahwa perlu penambahan sarana pengelolaan sampah dan peningkatan partisipasi masyarakat dengan pembangunan TPS 3R dengan sistem Bank Sampah.

e. Pembagian Zona-Zona Pengembangan

Untuk memudahkan monitoring program kegiatan maka dilakukan pembagian zona berdasarkan:

- Daerah dan tingkat pelayanan eksisting Daerah yang memiliki tingkat pelayanan tertinggi akan dijadikan daerah prioritas yang akan diutamakan dalam pengembangan nantinya.

- Kawasan strategis

Pembagian daerah berdasarkan kawasan strategis disesuaikan dengan RTRW Kabupaten Tanah Datar.

- Kepadatan penduduk

Wilayah dengan kepadatan penduduk tertinggi juga akan dijadikan daerah prioritas.

Zona pengembangan akan dibagi atas 5 zona dimana Zona A akan menjadi zona prioritas karena merupakan zona dengan kepadatan penduduk tertinggi, tingkat pelayanan tertinggi dan juga merupakan kawasan strategis sebagai kawasan ibukota Kabupaten Tanah Datar. Zona ini akan menjadi zona percontohan untuk zonazona lainnya. Pengembangan akan dilakukan per tahap sesuai dengan kondisi eksisting masing- 
masing zona. Lebih jelasnya perencanaan per tahapnya dapat diihat pada Tabel 2 dan Gambar 2.

Tabel 2. Pembagian Zona Pelayanan

\begin{tabular}{|c|l|}
\hline Zona & \multicolumn{1}{|c|}{ Daerah Pelayanan } \\
\hline A & Kecamatan Lima Kaum, \\
\hline B & $\begin{array}{l}\text { Kecamatan Tanjung Emas, Lintau Buo Utara, } \\
\text { Lintau Buo, dan Padang Ganting }\end{array}$ \\
\hline C & Kecamatan X Koto, Batipuh \\
\hline D & $\begin{array}{l}\text { Kecamatan Pariangan, Rambatan dan Batipuh } \\
\text { Selatan }\end{array}$ \\
\hline E & $\begin{array}{l}\text { Kecamatan Sungai Tarab, Salimpaung, Sungayang } \\
\text { dan Tanjung Baru }\end{array}$ \\
\hline
\end{tabular}

f. Rencana Kenaikan Tingkat dan Daerah pelayanan serta Target 3R

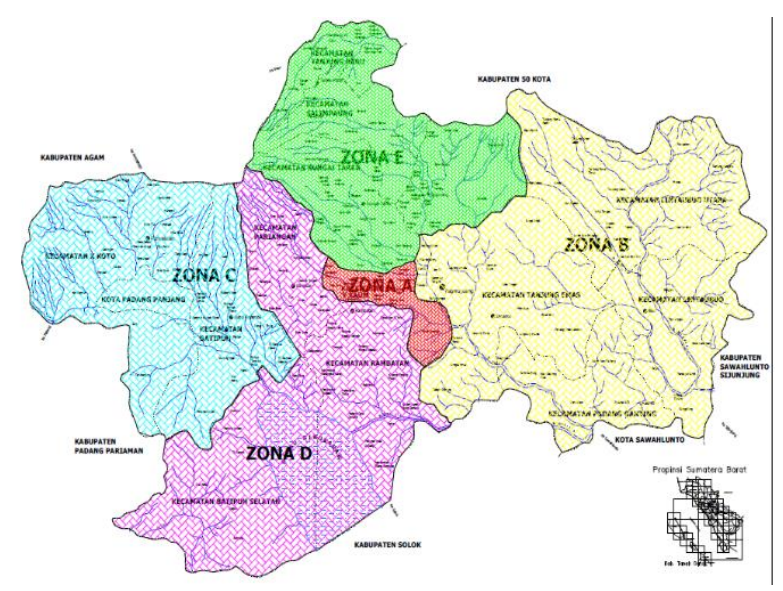

Gambar 2. Peta PerencanaanPembagian Zona Pengembangan

Berdasarkan zona pengembangan yang direncanakan, dilakukan peningkatan tingkat dan kondisi eksisting masing-masing zona. Lebih jelasnya dapat dilihat pada Tabel 3.

Tabel 3. Rencana Kenaikan Tingkat Pelayanan dan Interval Kenaikan, Daerah Pelayanan serta Target 3R

\begin{tabular}{|c|c|c|c|c|c|c|c|}
\hline \multirow{2}{*}{ No } & \multirow{2}{*}{ Zona } & \multirow{2}{*}{$\begin{array}{c}\text { Tingkat } \\
\text { Pelayanan }(\%)\end{array}$} & \multirow{2}{*}{$\begin{array}{l}\text { Interval Kenaikan } \\
\text { Tingkat Pelayanan } \\
\text { per tahun }\end{array}$} & \multirow{2}{*}{$\begin{array}{l}\text { Daerah Pelayanan } \\
\qquad(\%)\end{array}$} & \multicolumn{3}{|c|}{$\begin{array}{c}\text { Target 3R } \\
(\%)\end{array}$} \\
\hline & & & & & $\begin{array}{c}\text { Sampah } \\
\text { Total }\end{array}$ & $\begin{array}{c}\text { Sampah } \\
\text { Basah }\end{array}$ & $\begin{array}{l}\text { Sampah } \\
\text { Kering }\end{array}$ \\
\hline \multicolumn{8}{|c|}{ Eksisting } \\
\hline 1 & Zona A & 43,49 & 0 & 100 & 0 & 0 & +5 \\
\hline 2 & Zona B & 4,42 & 0 & 25 & 0 & 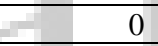 & 0 \\
\hline 3 & Zona C & 0,6 & 0 & 0 & 0 & 0 & 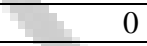 \\
\hline 4 & Zona D & - & 0 & 0 & 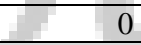 & 0 & 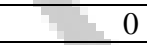 \\
\hline 5 & Zona E & - & 0 & $y=$ & 0 & 0 & +2 \\
\hline \multicolumn{8}{|c|}{ Tahap I (2016-2020) } \\
\hline 1 & Zona A & 60 & 3,2 & 100 & 5 & 3,75 & 1,25 \\
\hline 2 & Zona B & 25 & 4 & 30 & 3 & 2,25 & 0,75 \\
\hline 3 & Zona $\mathrm{C}$ & 20 & 4 & 2 & 5 & 1,5 & 0,5 \\
\hline 4 & Zona D & 15 & 3 & 20 & 5 & 1,5 & 0,5 \\
\hline 5 & Zona E & 15 & 4 & 20 & 5 & 1,5 & 0,5 \\
\hline \multicolumn{8}{|c|}{ Tahap II (2021-2025) } \\
\hline 1 & Zona A & 75 & 3 & 100 & 10 & 7,5 & 2,5 \\
\hline 2 & Zona B & 45 & 4 & 50 & 5 & 3,75 & 1,25 \\
\hline 3 & Zona $\mathrm{C}$ & 40 & 4 & 45 & 7 & 3,75 & 1,25 \\
\hline 4 & Zona D & 30 & 3 & 35 & 7 & 3,75 & 1,25 \\
\hline 5 & Zona E & 35 & 4 & 40 & 6 & 3,75 & 1,25 \\
\hline \multicolumn{8}{|c|}{ Tahap III (2026-2035) } \\
\hline 1 & Zona A & 100 & 2,5 & 100 & 20 & 11,25 & 3,75 \\
\hline 2 & Zona B & 85 & 4 & 90 & 10 & 7,5 & 2,5 \\
\hline 3 & Zona $\mathrm{C}$ & 80 & 4 & 85 & 9 & 6,75 & 2,25 \\
\hline 4 & Zona D & 65 & 3,5 & 70 & 8 & 6 & 2 \\
\hline 5 & Zona E & 75 & 4 & 80 & 7 & 5,25 & 1,75 \\
\hline
\end{tabular}

\section{Proyeksi Penduduk dan Proyeksi Persampahan yang Terlayani}

Metode yang dipakai dalam menghitung proyeksi pada Kabupaten Tanah Datar yaitu dengan membandingkan metode aritmatika, logaritma, eksponensial dan geometri. Metode yang terpilih adalah metode eksponensial dengan nilai $\mathrm{R}^{2}$ yang mendekati 1 dan nilai $\mathrm{S}$ yang paling kecil. Hasil rekapitulasi proyeksi masingmasing zona dapat dilihat pada Tabel 4.

Tabel 4. Proyeksi Penduduk dan Jumlah Sampah Kabupaten Tanah Datar per Tahap 


\begin{tabular}{|c|c|c|c|c|c|c|c|c|c|c|c|c|c|}
\hline \multicolumn{7}{|c|}{ Proyeksi Jumlah Penduduk per Zona } & \multirow{2}{*}{ Total } & \multicolumn{5}{|c|}{ Proyeksi Jumlah Sampah yang Terlayani per Zona } & \multirow{2}{*}{ Total } \\
\hline Tahap & Tahun & A & B & $\mathrm{C}$ & $\mathrm{D}$ & $\mathrm{E}$ & & A & B & $\mathrm{C}$ & $\mathrm{D}$ & $\mathrm{E}$ & \\
\hline $\mathrm{I}$ & 2020 & 38.453 & 96.336 & 75.573 & 62.553 & 79.636 & 352.551 & 169,642 & 425,002 & 333,402 & 275,963 & 351,327 & $1.555,335$ \\
\hline III & 2035 & 43.358 & 112.408 & 81.619 & 61.444 & 77.047 & 375.876 & 191,281 & 495,906 & 360,075 & 271,070 & 339,905 & $1.658,237$ \\
\hline
\end{tabular}

Ket $=*$ Tahun Eksisting

\section{Perencanaan Target Pemanfaatan Sampah dengan 3R}

Pemanfaatan sampah yang dilakukan adalah dengan daur ulang 3R di Tempat Pengolahan Sampah (TPS) 3R. pengolahan yang dilakukan untuk sampah basah adalah pengomposan dengan metode Takakura Susun dan Rotary Kiln, sedangkan untuk sampah kering menerapkan sistem Bank Sampah. Persentase pengolahan sampah basah dan kering adalah $75 \%$ dan $25 \%$.
Sistem Bank Sampah yang diterapkan sesuai dengan Kementerian Pekerjaan Umum (2014) yaitu $85 \%$ untuk pelanggan dan $15 \%$ untuk pengelola Bank Sampah. Pengolahan 3R ini akan terus meningkat setiap tahunnya sesuai dengan target 3R yang telah direncanakan. Jumlah sampah yang diolah dapat dilihat pada Tabel 5 dan jumlah sampah basah dan sampah kering dapat dilihat pada Tabel 6.

Tabel 5 Jumlah Sampah yang Diolah di TPS 3R per Tahap

\begin{tabular}{|c|c|c|c|c|c|c|c|c|c|c|c|}
\hline \multirow{3}{*}{ Tahap } & \multirow{3}{*}{ Tahun } & \multicolumn{5}{|c|}{ Kenaikan \% 3R } & \multicolumn{5}{|c|}{ Sampah yang akan diolah $\left(\mathrm{m}^{3} / \mathrm{hari}\right)$} \\
\hline & & \multicolumn{5}{|c|}{ Zona } & \multicolumn{5}{|c|}{ Zona } \\
\hline & & A & B & $\mathrm{C}$ & $\mathrm{D}$ & $\mathrm{E}$ & A & $\mathrm{B}$ & $\mathrm{C}$ & D & $\mathrm{E}$ \\
\hline & $2015 *$ & 0 & 0 & 0 & 0 & 0 & 0,000 & 0,000 & 0,000 & 0,000 & 0,000 \\
\hline $\mathrm{I}$ & 2020 & 5 & 3 & 2 & 2 & 2 & 5,089 & 3,188 & 1,334 & 0,828 & 1,054 \\
\hline II & 2025 & 10 & 5 & 5 & 5 & 5 & 13,278 & 10,067 & 6,841 & 4,109 & 6,082 \\
\hline III & 2035 & 20 & 10 & 9 & 8 & 7 & 38,256 & 42,152 & 25,925 & 14,096 & 17,845 \\
\hline
\end{tabular}

Ket $=*$ Tahun Eksisting

Tabel 6. Jumlah Sampah yang Diolah di TPS 3R per Tahap

\begin{tabular}{|c|c|c|c|c|c|c|c|c|c|c|c|}
\hline \multirow[b]{2}{*}{ Tahap } & \multirow[b]{2}{*}{ Tahun } & \multicolumn{2}{|c|}{ Zona A } & \multicolumn{2}{|c|}{ Zona B } & \multicolumn{2}{|c|}{ Zona $\mathrm{C}$} & \multicolumn{2}{|c|}{ Zona D } & \multicolumn{2}{|c|}{ Zona E } \\
\hline & & $\begin{array}{c}\text { Sampah } \\
\text { Basah } \\
\left(\mathrm{m}^{3} / \mathrm{h}\right)\end{array}$ & $\begin{array}{c}\text { Sampah } \\
\text { Kering } \\
\left(\mathrm{m}^{3} / \mathrm{h}\right)\end{array}$ & $\begin{array}{c}\text { Sampah } \\
\text { Basah } \\
\left(\mathrm{m}^{3} / \mathrm{h}\right)\end{array}$ & $\begin{array}{c}\text { Sampah } \\
\text { Kering } \\
\left(\mathrm{m}^{3} / \mathrm{h}\right)\end{array}$ & $\begin{array}{c}\text { Sampah } \\
\text { Basah } \\
\left(\mathrm{m}^{3} / \mathrm{h}\right)\end{array}$ & $\begin{array}{c}\text { Sampah } \\
\text { Kering } \\
\left(\mathrm{m}^{3} / \mathrm{h}\right)\end{array}$ & $\begin{array}{c}\text { Sampah } \\
\text { Basah } \\
\left(\mathrm{m}^{3} / \mathrm{h}\right)\end{array}$ & $\begin{array}{c}\text { Sampah } \\
\text { Kering } \\
\left(\mathrm{m}^{3} / \mathrm{h}\right)\end{array}$ & $\begin{array}{c}\text { Sampah } \\
\text { Basah } \\
\left(\mathrm{m}^{3} / \mathrm{h}\right)\end{array}$ & $\begin{array}{l}\text { Sampah } \\
\text { Kering } \\
\left(\mathrm{m}^{3} / \mathrm{h}\right)\end{array}$ \\
\hline & $2015 *$ & 0,000 & 0,000 & 0,000 & 0,000 & 0,000 & 0,000 & 0,000 & 0,000 & 0,000 & 0,000 \\
\hline $\mathrm{I}$ & 2020 & 3,817 & 1,272 & 2,416 & 0,771 & 1,011 & 0,323 & 0,628 & 0,200 & 0,799 & 0,255 \\
\hline II & 2025 & 9,958 & 3,319 & 7,631 & 2,436 & 5,186 & 1,656 & 3,115 & 0,994 & 4,610 & 1,472 \\
\hline III & 2035 & 28,692 & 9,564 & 31,951 & 10,201 & 19,651 & 6,274 & 10,684 & 3,411 & 13,527 & 4,318 \\
\hline
\end{tabular}

Ket $=*$ Tahun Eksisting

\section{Pemilihan Sistem Pemanfaatan Sampah}

\section{Aspek Teknis}

Perencanaan aspek teknis pengelolaan sampah Kabupaten Tanah Datar meliputi:

a. Sistem pewadahan

Jenis wadah komunal yang digunakan adalah kontainer dengan kapasitas $8 \mathrm{~m}^{3} /$ hari. Sampah yang ditampung pada kontainer ini adalah sampah tercampur yang berasal dari kawasan yang belum melakukan pengolahan 3R. Sampah yang telah dikumpulkan di kontainer selanjutnya dibawa ke TPA Bukit Sangkiang tanpa dilakukan pengolahan terlebih dahulu. Selain itu kontainer juga diletakan pada TPS 3R untuk menampung residu sampah yang berasal dari pengolahan sampah di TPS 3R. Umur wadah yang digunakan sesuai dengan SNI-3242-2008 tentang Pengelolaan Sampah di Pemukiman yaitu 5-8 tahun, untuk itu dipilih 8 tahun.

b. Sistem pengumpulan

Pola pengumpulan yang direncanakan adalah pola individual tidak langsung dan komunal langsung. Pola pengumpulan individual tidak langsung diterapkan pada daerah yang telah dibangun bangunan pengolahan 3R. Sarana yang digunakan untuk pengumpulan individual tidak langsung adalah becak motor dengan kapasitas 1,5 $\mathrm{m}^{3}$ dan tidak bersekat. Becak motor yang mengangkut sampah basah ke TPS 3R dibedakan dengan pemberian tanda dan label khusus TPS 3R sedangkan becak motor yang membawa sampah tercampur ke kontainer tidak diberi tanda.

c. Sistem pengangkutan 
Pengangkutan sampah ke TPA menggunakan armroll truck dengan kapasitas $8 \mathrm{~m}^{3} / \mathrm{hari}$. Pengangkutan dilakukan sebanyak dua ritasi, dengan asumsi umur pakai kendaraan sama dengan kontainer yaitu 8 tahun. Selain untuk mengangkut sampah dari pengumpulan komunal langsung, truk ini juga mengangkut kontainer di TPS 3R secara berkala.

d. Sistem pengolahan sampah

Pengolahan sampah yang direncanakan adalah TPS $3 R$ yang terdiri dari dua tipe Tipe I dengan rotary kiln kapasitas $4,5 \mathrm{~m}^{3} /$ hari dan tipe II dengan Takakura Susun kapasitas 9 $\mathrm{m}^{3} /$ hari. Pengolahan yang dilakukan adalah pengomposan sampah basah dan daur ulang untuk sampah kering seperti plastik dan kertas dengan sistem Bank Sampah.

e. TPA

Sistem yang digunakan adalah sanitary landfill dimana TPA yang ada berkapasitas 3 Ha dengan total sampah yang masuk per hari $48,28 \mathrm{~m}^{3} /$ hari.

\section{PROGRAM PENGEMBANGAN}

\section{Jumlah Pewadahan}

Pewadahan yang digunakan ada dua yaitu kontainer untuk sampah di TPS dan kontainer untuk menampung residu sampah di TPS 3R. jumlah kontainer ini dapat dilihat pada Tabel 7. Sistem pewadahan yang direncanakan adalah terpilah untuk sampah yang akan diangkut ke TPS 3R sedangkan untuk sampah yang akan diangkut ke kontainer adalah pewadahan tercampur. Wadah yang digunakan adalah kontainer dengan kapasitas $8 \mathrm{~m}^{3}$.

\section{Jumlah Sarana Pengumpulan}

Sarana pengumpulan yang digunakan adalah becak motor dengan kaspistas 1,5 $\mathrm{m}^{3} /$ hari. Becak motor yang digunakan ada dua yaitu becak motor yang langsung membawa sampah ke kontainer dan becak motor yang mengangkut sampah ke TPS 3R. Untuk sampah yang akan dibawa ke TPS 3R ini hanya sampah basah saja, sedangkan sampah kering akan dibawa oleh masyarakat itu sendiri dan ditabung di Bank Sampah. Lokasi penyebaran becak motor ini adalah lokasi yang memiliki bangunan fisik TPS 3R. Lebih jelasnya dapat dilihat pada Tabel 8.

Tabel 7. Jumlah Pewadahan Kabupaten Tanah Datar Jumlah Kontainer per Zona

\begin{tabular}{rrrrrrrrrrrr}
\hline \multicolumn{10}{c}{ Sampah yang Dibuang ke } & \multicolumn{1}{c}{ Residu } & \multirow{2}{*}{ Total } \\
& \multicolumn{1}{c}{ TPA } & B & C & D & E & A & B & C & D & E & \\
\hline $2015^{*}$ & 6 & 0 & 0 & 0 & 0 & 0 & 0 & 0 & 0 & 0 & 6 \\
\hline 2016 & 9 & 5 & 2 & 1 & 1 & 1 & 0 & 0 & 0 & 0 & 19 \\
\hline 2017 & 10 & 7 & 3 & 2 & 3 & 1 & 0 & 0 & 0 & 0 & 26 \\
\hline 2018 & 11 & 9 & 5 & 3 & 4 & 1 & 1 & 1 & 0 & 1 & 36 \\
\hline 2019 & 12 & 11 & 7 & 4 & 5 & 1 & 1 & 1 & 1 & 1 & 44 \\
\hline 2020 & 12 & 13 & 8 & 5 & 6 & 1 & 1 & 1 & 1 & 1 & 49 \\
\hline 2021 & 13 & 15 & 10 & 6 & 8 & 1 & 1 & 1 & 1 & 1 & 57 \\
\hline 2022 & 13 & 16 & 11 & 7 & 10 & 1 & 1 & 1 & 1 & 1 & 62 \\
\hline 2023 & 14 & 19 & 13 & 8 & 11 & 1 & 1 & 1 & 1 & 1 & 70 \\
\hline 2024 & 15 & 22 & 15 & 9 & 13 & 1 & 1 & 1 & 1 & 1 & 79 \\
\hline 2025 & 15 & 24 & 16 & 10 & 15 & 1 & 1 & 1 & 1 & 1 & 85 \\
\hline 2026 & 16 & 26 & 18 & 11 & 16 & 1 & 1 & 1 & 1 & 1 & 92 \\
\hline 2027 & 16 & 28 & 20 & 12 & 18 & 1 & 1 & 1 & 1 & 1 & 99 \\
\hline 2028 & 16 & 31 & 21 & 13 & 19 & 1 & 1 & 1 & 1 & 1 & 105 \\
\hline 2029 & 17 & 33 & 22 & 14 & 21 & 1 & 1 & 1 & 1 & 1 & 112 \\
\hline 2030 & 17 & 35 & 24 & 15 & 22 & 1 & 1 & 1 & 1 & 1 & 118 \\
\hline 2031 & 18 & 37 & 26 & 16 & 24 & 1 & 1 & 1 & 1 & 1 & 126 \\
\hline 2032 & 18 & 40 & 27 & 17 & 25 & 1 & 1 & 1 & 1 & 1 & 132 \\
\hline 2033 & 18 & 43 & 29 & 18 & 27 & 1 & 1 & 1 & 1 & 1 & 140 \\
\hline 2034 & 19 & 44 & 31 & 19 & 28 & 1 & 1 & 1 & 1 & 1 & 146 \\
\hline 2035 & 19 & 47 & 33 & 20 & 30 & 1 & 1 & 1 & 1 & 1 & 154 \\
\hline Ket=* Tahun $)$ & Eksisting (KLH Tanah Datar, 2012$)$ & & &
\end{tabular}

\section{Tabel 8. Jumlah Becak Motor}

\begin{tabular}{|c|c|c|c|c|c|c|c|c|c|c|c|}
\hline \multirow{3}{*}{ Tahun } & \multicolumn{10}{|c|}{ Jumlah Becak Motor per Zona } & \multirow[b]{3}{*}{ Total } \\
\hline & \multicolumn{5}{|c|}{ Becak Motor ke TPS 3R } & \multicolumn{5}{|c|}{ Becak Motor ke Kontainer } & \\
\hline & $\mathrm{A}$ & $\mathrm{B}$ & $\mathrm{C}$ & $\mathrm{D}$ & $\mathrm{E}$ & $\mathrm{A}$ & $\mathrm{B}$ & $\mathrm{C}$ & $\mathrm{D}$ & $\mathrm{E}$ & \\
\hline $2015^{*}$ & 0 & 0 & 0 & 0 & 0 & 0 & 0 & 0 & 0 & 0 & 0 \\
\hline 2016 & 1 & 0 & 0 & 0 & 0 & 7 & 0 & 0 & 0 & 0 & 8 \\
\hline 2017 & 1 & 0 & 0 & 0 & 0 & 7 & 0 & 0 & 0 & 0 & 8 \\
\hline 2018 & 1 & 1 & 1 & 0 & 1 & 8 & 4 & 2 & 0 & 4 & 22 \\
\hline 2019 & 1 & 1 & 1 & 1 & 1 & 8 & 6 & 2 & 2 & 5 & 28 \\
\hline 2020 & 1 & 1 & 1 & 1 & 1 & 17 & 7 & 2 & 2 & 7 & 40 \\
\hline 2021 & 2 & 1 & 1 & 1 & 1 & 19 & 9 & 2 & 2 & 7 & 45 \\
\hline 2022 & 2 & 1 & 1 & 1 & 1 & 19 & 11 & 2 & 2 & 7 & 47 \\
\hline 2023 & 3 & 2 & 1 & 1 & 2 & 21 & 11 & 6 & 2 & 7 & 56 \\
\hline 2024 & 3 & 2 & 1 & 1 & 2 & 21 & 12 & 7 & 3 & 9 & 61 \\
\hline 2025 & 3 & 3 & 1 & 1 & 2 & 21 & 13 & 8 & 3 & 10 & 65 \\
\hline 2026 & 3 & 4 & 2 & 1 & 2 & 24 & 13 & 8 & 11 & 11 & 79 \\
\hline 2027 & 3 & 6 & 2 & 1 & 2 & 24 & 13 & 9 & 12 & 12 & 84 \\
\hline 2028 & 4 & 6 & 2 & 2 & 2 & 25 & 13 & 11 & 13 & 12 & 90 \\
\hline 2029 & 4 & 6 & 3 & 2 & 2 & 26 & 13 & 12 & 14 & 13 & 95 \\
\hline 2030 & 4 & 6 & 3 & 2 & 2 & 27 & 13 & 12 & 14 & 14 & 97 \\
\hline 2031 & 5 & 6 & 3 & 2 & 2 & 28 & 20 & 14 & 14 & 15 & 109 \\
\hline 2032 & 5 & 6 & 4 & 3 & 2 & 29 & 20 & 14 & 14 & 21 & 118 \\
\hline 2033 & 6 & 6 & 4 & 3 & 2 & 31 & 20 & 14 & 15 & 23 & 124 \\
\hline 2034 & 6 & 7 & 4 & 3 & 2 & 31 & 20 & 18 & 19 & 24 & 134 \\
\hline 2035 & 6 & 7 & 5 & 3 & 2 & 32 & 20 & 18 & 19 & 24 & 136 \\
\hline
\end{tabular}

\section{Jumlah Sarana Pengangkutan}

Sarana pengangkutan yang digunakan adalah armroll truck dengan sistem HCS. Pengangkutan dilakukan dua kali sehari karena menimbang jarak dan jumlah sampah yang akan diangkut ke TPA. Sampah yang diangkut adalah sampah yang telah ditampung di kontainer dan residu sampah dari TPS 3R. Kapasitas armroll truck 
yang digunakan adalah $8 \mathrm{~m}^{3}$. Lebih jelasnya dapat dilihat pada Tabel 9.

Tabel 9. Jumlah Kebutuhan Truk

\begin{tabular}{|c|c|c|c|c|c|c|}
\hline \multirow{2}{*}{ Tahun } & \multicolumn{5}{|c|}{ Jumlah truk per Zona } & \multirow{2}{*}{ Total } \\
\hline & A & $\mathrm{B}$ & $\mathrm{C}$ & $\mathrm{D}$ & $\mathrm{E}$ & \\
\hline $2015^{*}$ & 6 & 0 & 0 & 0 & 0 & 6 \\
\hline 2016 & 5 & 3 & 1 & 1 & 1 & 11 \\
\hline 2017 & 6 & 4 & 2 & 1 & 2 & 15 \\
\hline 2018 & 6 & 5 & 3 & 2 & 3 & 19 \\
\hline 2019 & 7 & 6 & 4 & 3 & 3 & 23 \\
\hline 2020 & 7 & 7 & 5 & 3 & 4 & 26 \\
\hline 2021 & 7 & 8 & 6 & 4 & 5 & 30 \\
\hline 2022 & 7 & 9 & 6 & 4 & 6 & 32 \\
\hline 2023 & 8 & 10 & 7 & 5 & 6 & 36 \\
\hline 2024 & 8 & 12 & 8 & 5 & 7 & 40 \\
\hline 2025 & 8 & 13 & 9 & 6 & 8 & 44 \\
\hline 2026 & 9 & 14 & 10 & 6 & 9 & 48 \\
\hline 2027 & 9 & 15 & 11 & 7 & 10 & 52 \\
\hline 2028 & 9 & 16 & 11 & 7 & 10 & 53 \\
\hline 2029 & 9 & 17 & 12 & 8 & 11 & 57 \\
\hline 2030 & 9 & 18 & 13 & 8 & 12 & 60 \\
\hline 2031 & 10 & 19 & 14 & 9 & 13 & 65 \\
\hline 2032 & 10 & 21 & 14 & 9 & 13 & 67 \\
\hline 2033 & 10 & 22 & 15 & 10 & 14 & 71 \\
\hline 2034 & 10 & 23 & 16 & 10 & 15 & 74 \\
\hline 2035 & 10 & 24 & 17 & 11 & 16 & 78 \\
\hline
\end{tabular}

Ket $=*$ Tahun Eksisting (KLH Tanah Datar, 2012)

\section{Sistem Pengolahan Sampah}

Pengelolaan sampah Kabupaten Tanah Datar direncanakan dilakukan pemilahan dari sumber lalu diangkut ke tempat pengolahan sampah yang berupa TPS $3 \mathrm{R}$ yang kemudian residunya dibuang ke TPA. TPS 3R yang akan direncanakan adalah berbasis masyarakat dengan sistem Bank Sampah. Masyarakat berperan serta untuk memilah dan mengolah serta menabung sampah. Masyarakat akan membawa sampah kering ke Bank Sampah sesuai dengan jenis sampah yang ditetapkan oleh TPS 3R tersebut yang kemudian akan diuangkan, sementara sampah basah yang akan dikompos dijemput dengan becak motor yang khusus ke TPS 3R ini. Sistem bagi hasil yang ditetapkan sesuai dengan Kementerian Pekerjaan Umum (2014) yaitu 85\% untuk pelanggan dan $15 \%$ untuk pengelola Bank Sampah.

Kapasitas TPS 3R yang akan didirikan yaitu dengan Tipe I merupakan TPS 3R yang telah ada, namun akan dilakukan perluasan bangunan hingga mencapai luas $200 \mathrm{~m}^{2}$ karena TPS 3R ini telah melayani $200 \mathrm{KK}$ dengan kapasitas pengolahan $4,5 \mathrm{~m}^{3} /$ hari, Tipe II yaitu TPS $3 \mathrm{R}$ dengan kapasitas $600 \mathrm{KK}$ dan luas $1400 \mathrm{~m}^{2}$ dengan kapasitas $9 \mathrm{~m}^{3} /$ hari. Pemilihan jenis TPS
3R ini berpedoman kepada Tata Cara Penyelenggaraan Umum Tempat Pengolahan Sampah (TPS) 3R Berbasis Masyarakat di Kawasan Permukiman, yang diterbitkan oleh Kementerian Pekerjaan Umum Direktorat Jenderal Cipta Karya (2014), selain itu juga disesuaikan dengan jumlah sampah yang akan diolah. Lebih jelasnya dapat dilihat pada Tabel 10.

Tabel 10. Spesifikasi TPS 3R Tipe I dan Tipe II

\begin{tabular}{|c|c|c|c|}
\hline No. & Aspek & Tipe I & Tipe II \\
\hline 1. & Luas total $\left(\mathrm{m}^{2}\right)$ & 200 & 1600 \\
\hline 2 & Jumlah KK & 200 & 600 \\
\hline 3 & Teknologi Komposting & Rotary kiln & $\begin{array}{r}\text { Takakura } \\
\text { susun } \\
\end{array}$ \\
\hline 4 & Jumlah (unit) & 5 & 56 \\
\hline 5 & Beban Kerja $\left(\mathrm{m}^{3}\right)$ & 4,5 & 6 \\
\hline 6 & $\begin{array}{l}\text { Luas area pencacahan } \\
\left(\mathrm{m}^{2}\right)\end{array}$ & 28 & 56 \\
\hline 7 & $\begin{array}{l}\text { Luas area } \\
\text { pengomposan }\left(\mathrm{m}^{2}\right)\end{array}$ & 20 & 28 \\
\hline 8 & $\begin{array}{l}\text { Luas area pengayakan } \\
\left(\mathrm{m}^{2}\right)\end{array}$ & 8 & 24 \\
\hline 9 & $\begin{array}{l}\text { Luas area pengemasan } \\
\left(\mathrm{m}^{2}\right)\end{array}$ & 7 & 28 \\
\hline 10 & $\begin{array}{l}\text { Luas area pencucian } \\
\text { sampah kering }\left(\mathrm{m}^{2}\right)\end{array}$ & 8 & 16 \\
\hline 11 & Luas gudang $\left(\mathrm{m}^{2}\right)$ & 8 & 16 \\
\hline 12 & $\begin{array}{l}\text { Luas area kontainer } \\
\left(\mathrm{m}^{2}\right)\end{array}$ & 2 & \\
\hline 13 & $\begin{array}{l}\text { Luas area kantor dan } \\
\text { bank sampah }\left(\mathrm{m}^{2}\right)\end{array}$ & 24 & 24 \\
\hline
\end{tabular}

\section{Sebaran TPS 3R}

Pengolahan sampah ini diprioritaskan untuk Zona A karena pada zona ini memiliki tingkat pelayanan yang paling tinggi. Sementara untuk zona yang lain tetap dilakukan pengolahan namun lebih mengutamakan pembangunan sarana dan prasarana aspek teknis operasional. Pengoperasian dan lokasi pembangunan pengolahan ini dapat dilihat pada Gambar 3 dimana pembangunannya dilakukan satu tahun sebelum tahun operasional. Penambahan bangunan TPS 3R ini berdasarkan peningkatan jumlah sampah yang akan diolah yang disesuaikan dengan kapasitas TPS 3R itu sendiri. Lebih jelasnya dapat dilihat pada Gambar 3.

Teknologi pengomposan yang digunakan dengan teknologi modern rotary kiln dan teknologi sederhana berupa metode Takakura Susun. Pemakaian rotary kiln ini diterapkan pada TPS 3R Tipe I karena telah terdapat unit rotary kiln di TPS 3R eksisting, serta proses pengomposan berlangsung lebih cepat. TPS 3R Tipe II 
menerapkan metode Takakura Susun karena harganya yang lebih murah, pengomposan lebih sederhana, tidak membutuhkan lahan yang besar dan karena menimbang besarnya kapasitas sampah yang akan diolah sehingga membutuhkan unit pengolahan kompos dalam jumlah yang lebih besar, dengan demikian metode ini lebih efektif untuk diterapkan dari segi ekonomis.

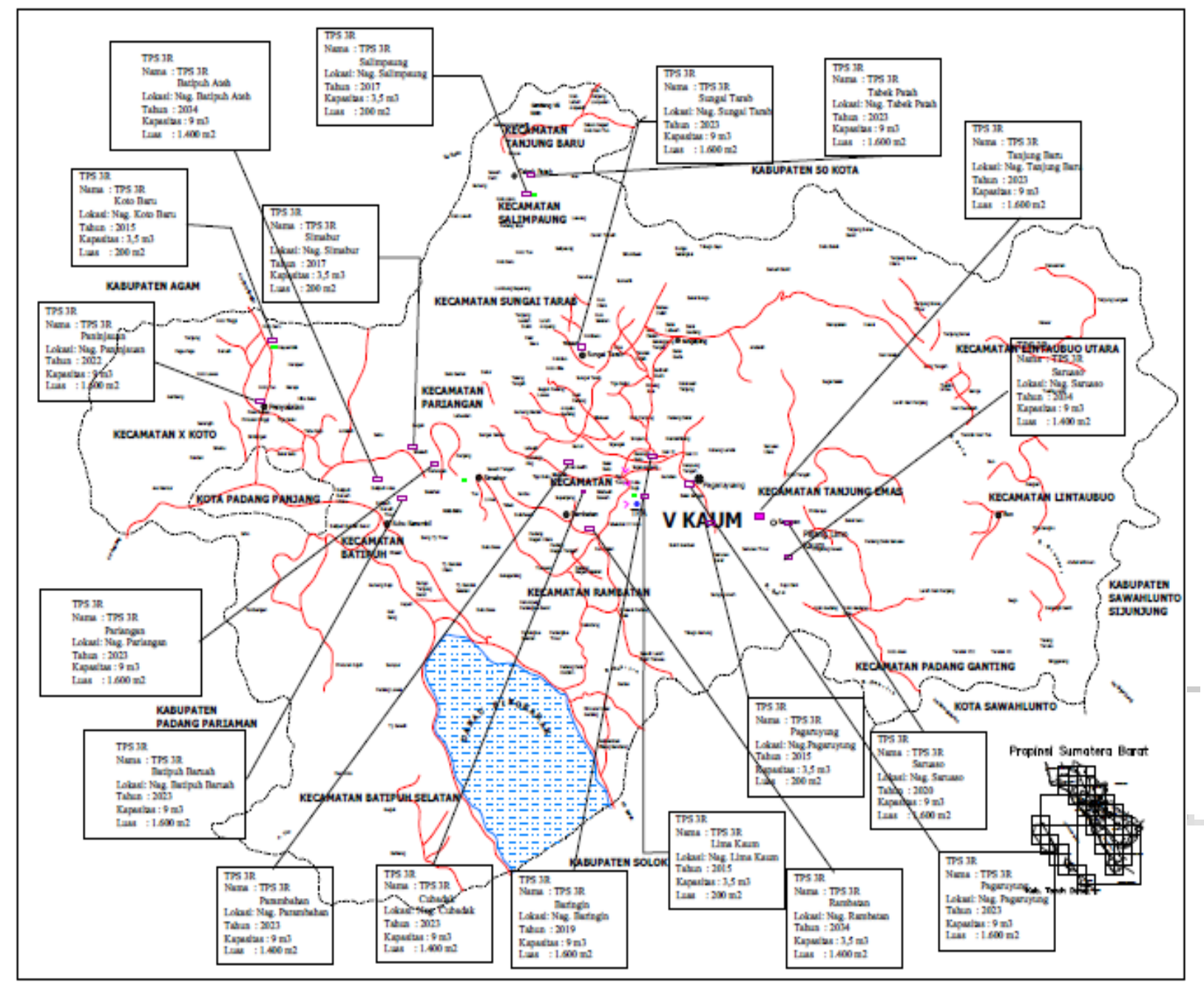

Gambar 3. Peta Sebaran TPS 3R Tahun 2016-2035

\section{Skenario Pengelolaan Sampah}

Flowchart skenario pengelolaan sampah Kabupaten Tanah Datar bertujuan untuk memudahkan dan memberi gambaran lebih sederhana mengenai pola pengelolaan sampah yang telah direncanakan. Dapat dilihat bahwa terjadi pengurangan sampah yang masuk ke TPA. Sampah yang dibuang ke TPA berasal dari residu sampah yang didaur ulang dan sampah yang dibuang langsung ke kontainer. Lebih jelasnya skenario pengelolaan persampahan akhir perencanaan dapat dilihat pada Gambar 4. 


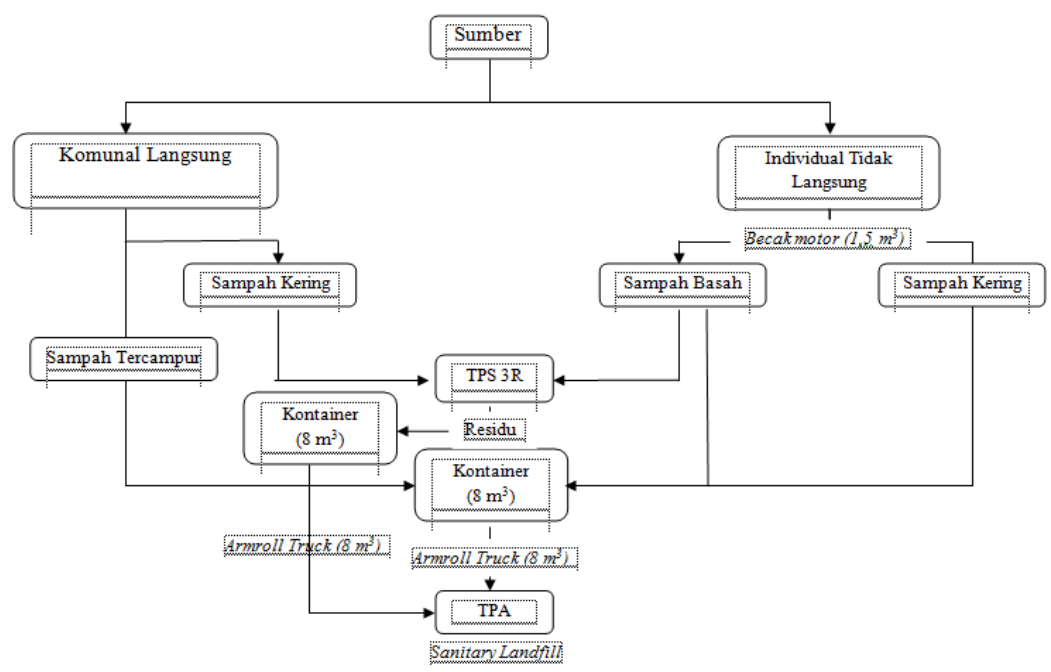

Gambar 4. Flowchart Skenario Perencanaan Pengelolaan Sampah

\section{Analisis Perbandingan (Konvensional vs Sistem 3R)}

\section{Sarana pewadahan}

Setelah dilakukan perhitungan timbulan sampah maka dapat dibandingkan jumlah wadah yang dibutuhkan dengan dan tanpa pengolahan $3 \mathrm{R}$ per tahapnya. Lebih jelasnya dapat dilihat pada Tabel 11.

Dari Tabel 11 tersebut dapat dilihat perbandingan jumlah kontainer dengan sistem konvensional lebih banyak dibandingkan dengan jumlah wadah yang dibutuhkan dengan melakukan pengolahan.

Tabel 12. Perbandingan Sarana Pengumpul dan Pengangkut Sistem Konvensional vs Sistem 3R

\begin{tabular}{|c|c|c|c|c|c|}
\hline \multirow{3}{*}{ Tahap } & \multirow{3}{*}{$\begin{array}{c}\text { Timbulan } \\
\text { Sampah } \\
\text { Terlayani }\left(\mathrm{m}^{3} / \mathrm{h}\right) \\
\end{array}$} & \multicolumn{2}{|c|}{ Jumlah Sarana Pengumpul } & \multicolumn{2}{|c|}{ Sarana Pengangkut } \\
\hline & & Konvensional & Sistem 3R & Konvensional & Sistem 3R \\
\hline & & Becak Motor & Becak Motor & Amroll Truck & Amroll Truck \\
\hline $\mathrm{I}$ & 368,809 & 307 & 40 & 23 & 22 \\
\hline II & 674,767 & 562 & 65 & 42 & 40 \\
\hline III & 1331,985 & 1110 & 136 & 83 & 75 \\
\hline
\end{tabular}

Dari Tabel 12 dapat dilihat bahwa jumlah becak motor yang digunakan apabila tidak melakukan pengolahan 3R jauh lebih banyak daripada jumlah becak motor yang melakukan pengolahan 3R. Hal ini dikarenakan masyarakat yang harusnya berpartisipasi dalam membuang sampah ke kontainer tetap dilayani oleh becak motor. Sedangkan untuk armroll truck dapat disimpulkan bahwa jumlah armroll truck konvensional lebih banyak dibandingkan dengan jumlah armroll truck yang mengangkut sampah setelah diolah.

3. Sampah yang masuk ke TPA
Tabel 11. Perbandingan Jumlah Wadah Sistem Konvensional Vs Sistem 3R

\begin{tabular}{|c|c|c|c|}
\hline \multirow{2}{*}{ Tahap } & \multirow{2}{*}{$\begin{array}{l}\text { Timbulan } \\
\text { sampah } \\
\text { Terlayani } \\
\left(\mathrm{m}^{3} / \mathrm{h}\right)\end{array}$} & \multicolumn{2}{|c|}{ Jumlah Pewadahan Komunal } \\
\hline & & $\begin{array}{c}\text { Konvensional } \\
\text { Kontainer } 8 \mathrm{~m}^{3}\end{array}$ & $\begin{array}{c}\text { Sistem 3R } \\
\text { Kontainer } 8 \mathrm{~m}^{3}\end{array}$ \\
\hline I & 368,809 & 46 & 44 \\
\hline II & 674,767 & 84 & 80 \\
\hline III & 1331,985 & 166 & 149 \\
\hline
\end{tabular}

2. Sarana Pengumpulan dan Pengangkutan

Perbandingan jumlah sarana pengumpul dan pangangkut dapat dilihat pada Tabel 12. Jumlah sampah yang dibuang ke TPA dengan sistem konvensional dan $3 \mathrm{R}$ dapat dilihat pada Tabel 13. 
Tabel 13. Perbandingan Jumlah Sampah yang Masuk ke TPA dengan Sistem Konvensional vs Sistem 3R

\begin{tabular}{crr}
\hline \multirow{2}{*}{ Tahap } & \multicolumn{2}{c}{ Jumlah timbulan sampah Terlayani $\left(\mathrm{m}^{3} / \mathrm{h}\right)$} \\
\cline { 2 - 3 } & Konvensional & \multicolumn{1}{c}{ Sistem 3R } \\
\hline I & 368,809 & 358,219 \\
\hline II & 674,767 & 637,560 \\
\hline III & 1331,985 & 1204,569 \\
\hline
\end{tabular}

Berdasarkan Tabel 13 dapat disimpulkan bahwa dengan dilakukannya pengolahan 3R di Kabupaten Tanah Datar dapat mereduksi jumlah sampah yang akan masuk ke TPA Bukit Sangkiang.

\section{RENCANA TINDAK LANJUT}

Rencana tindak lanjut ini merupakan rencana awal program kegiatan yang akan dilaksanakan pada periode jangka pendek selama lima tahun pertama (2016-2020). Rencana ini meliputi aspek teknis dan non teknis yang diperhitungkan akan memerlukan anggaran sebesar $\mathrm{Rp}$. 12.233.455,-. Lebih jelasnya dapat dilihat pada Tabel 14.

Tabel 14. Rekapitulasi Program Kegiatan Jangka Pendek Tahun 2016-2020

\begin{tabular}{|c|c|c|c|c|c|c|c|c|}
\hline \multirow{3}{*}{$\begin{array}{c}\text { No } \\
\text {. }\end{array}$} & \multirow{3}{*}{ Program dan Kegiatan } & \multirow{3}{*}{ Detail Lokasi } & \multicolumn{6}{|c|}{ Kebutuhan Penanganan Menyeluruh } \\
\hline & & & \multirow{2}{*}{ Satuan } & \multicolumn{5}{|c|}{ Jumlah } \\
\hline & & & & 2016 & 2017 & 2018 & 2019 & 2020 \\
\hline A. & Aspek Teknis & & & & & & & \\
\hline \multirow[t]{4}{*}{1.} & $\begin{array}{l}\text { Penambahan sarana pewadahan, pengumpulan dan } \\
\text { pengangkutan sampah }\end{array}$ & \multirow{4}{*}{$\begin{array}{c}\text { Kabupaten Tanah } \\
\text { Datar }\end{array}$} & & & & & & \\
\hline & a.Kontainer $8 \mathrm{~m} 3$ & & unit & 14 & 6 & 9 & 7 & 5 \\
\hline & b. Becak motor $1,5 \mathrm{~m} 3$ & & unit & 8 & 0 & 14 & 6 & 12 \\
\hline & d. Amroll Truck & & unit & 4 & 3 & 5 & 3 & 4 \\
\hline 2. & Optimalisasi TPS 3R Tipe I & Nagari Lima Kaum & paket & 1 & & & & \\
\hline \multirow[t]{5}{*}{3} & Pembangunan TPS 3R Tipe I & Nagari Pagaruyung & paket & & 1 & & 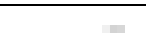 & \\
\hline & 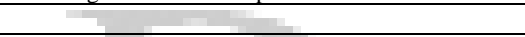 & Nagari Koto baru & paket & & 1 & & +4 & \\
\hline & 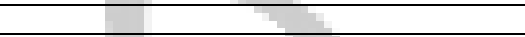 & Nagari Salimpaung & paket & & 1 & & 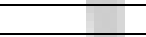 & \\
\hline & +2 & Nagari Simabur & paket & & & 1 & 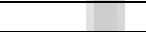 & \\
\hline & 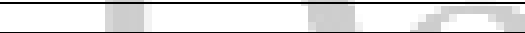 & Nagari Baringin & paket & + & 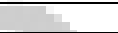 & 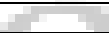 & 1 & +1 \\
\hline $\mathrm{B}$ & Aspek non Teknis & 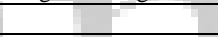 & & 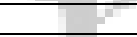 & +1 & + & 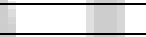 & +5 \\
\hline \multirow[t]{6}{*}{1.} & $\begin{array}{l}\text { Sosialisasi dan penyuluhan tentang pemilahan } \\
\text { sampah dan pengolahan sampah 3R (reduce-reuse- } \\
\text { recycle). }\end{array}$ & Nagari Lima Kaum & Kali & 3 & & & & \\
\hline & 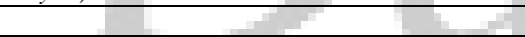 & Nagari Pagaruyung & Kali & 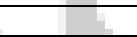 & $+r$ & 3 & $=$ & \\
\hline & 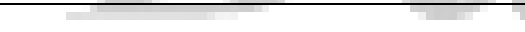 & Nagari Koto baru & Kali & 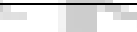 & 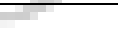 & 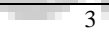 & $x$ & $x^{2}$ \\
\hline & & Nagari Salimpaung & Kali & & & 3 & & \\
\hline & & Nagari Simabur & Kali & & & & 3 & \\
\hline & & Nagari Baringin & Kali & 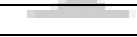 & & & & 3 \\
\hline 2 & $\begin{array}{l}\text { Sosialisasi peraturan, perundangan dan sosialisai } \\
\text { tentang Perda pengelolaan sampah serta tetribusi } \\
\text { pelayanan persampahan/kebersihan }\end{array}$ & $\begin{array}{l}\text { Kabupaten Tanah } \\
\text { Datar }\end{array}$ & Kali & 1 & 1 & 1 & 1 & 1 \\
\hline \multirow[t]{6}{*}{3} & $\begin{array}{l}\text { Penyuluhan mengenai sampah ke beberapa sekolah } \\
\text { dan nagari-nagari serta pengenalan cara pembuatan } \\
\text { kompos }\end{array}$ & Nagari Lima Kaum & Kali & 1 & 1 & 1 & 1 & 1 \\
\hline & & Nagari Pagaruyung & Kali & 1 & 1 & 1 & 1 & 1 \\
\hline & & Nagari Koto baru & Kali & 1 & 1 & 1 & 1 & 1 \\
\hline & & Nagari Salimpaung & Kali & 1 & 1 & 1 & 1 & 1 \\
\hline & & Nagari Simabur & Kali & 1 & 1 & 1 & 1 & 1 \\
\hline & & Nagari Baringin & Kali & 1 & 1 & 1 & 1 & 1 \\
\hline 4 & $\begin{array}{l}\text { Penguatan kelembagaan bidang persampahan (pola } \\
\text { hubungan RT, RW, kelurahan, kecamatan dengan } \\
\text { KLH Kabupaten Tanah Datar) }\end{array}$ & $\begin{array}{l}\text { Kabupaten Tanah } \\
\text { Datar }\end{array}$ & Kali & 1 & 1 & 1 & 1 & 1 \\
\hline \multirow[t]{6}{*}{5} & $\begin{array}{l}\text { Pelatihan tentang pengolahan sampah untuk } \\
\begin{array}{l}\text { Kelompok Swadaya Masyarakat (KSM) yang } \\
\text { peduli lingkungan }\end{array}\end{array}$ & Nagari Lima Kaum & Kali & 1 & & & & \\
\hline & & Nagari Pagaruyung & Kali & & & 1 & & \\
\hline & & Nagari Koto baru & Kali & & & 1 & & \\
\hline & & Nagari Salimpaung & Kali & & & 1 & & \\
\hline & & Nagari Simabur & Kali & & & & 1 & \\
\hline & & Nagari Baringin & Kali & & & & & 1 \\
\hline \multirow[t]{6}{*}{6} & Sosialisasi tentang Bank Sampah. & Nagari Lima Kaum & Kali & 1 & & & & \\
\hline & & Nagari Pagaruyung & Kali & & & 1 & & \\
\hline & & Nagari Koto baru & Kali & & & 1 & & \\
\hline & & Nagari Salimpaung & Kali & & & 1 & & \\
\hline & & Nagari Simabur & Kali & & & & 1 & \\
\hline & & Nagari Baringin & Kali & & & & & 1 \\
\hline
\end{tabular}




\section{SIMPULAN}

Berdasararkan hasil pengembangan persampahan Kabupaten Tanah Datar dapat disimpulkan:

1. Kondisi persampahan Kabupaten Tanah Datar masih minim sekali, karena hanya $3,71 \%$ sampah yang dapat terangkut ke TPA;

2. Perencanaan tingkat pelayanan minimum adalah $60 \%$ dari sampah keseluruhan sesuai dengan PerMen PU No. 21 Tahun 2006, untuk memudahkan monitoring maka dilakukan pembagian zona untuk setiap daerah pelayanan.

3. Perencanaan aspek teknis meliputi:

a. Pola pewadahan yang digunakan adalah terpilah yaitu sampah basah dan sampah kering. Wadah yang digunakan berupa kontainer dengan kapasitas $8 \mathrm{~m}^{3}$.

b. Pola pengumpulan yang direncanakan adalah pola komunal langsung dan individual tidak langsung. Alat pengumpul yang digunakan berupa becak motor dengan kapasitas $1,5 \mathrm{~m}^{3}$ dan tidak bersekat.

c. Pola pengangkutan yang digunakan adala Hauled Container System (HCS) menggunakan armroll truck.

d. Bangunan pengolahan 3R berupa TPS 3R dengan sistem Bank Sampah yang terdiri atas dua tipe yaitu Tipe I dengan luas $200 \mathrm{~m}^{2}$ dan Tipe II dengan luas $1400 \mathrm{~m}^{2}$. Komposter yang digunakan berupa rotary kiln dan Takakura Susun.

e. Metoda landfill direncanakan adalah sanitary landfill.

4. Peran serta masyarakat perlu ditingkatkan dalam pengelolaan ini, hal ini juga harus didukung dengan peraturan yang tegas dari pemerintah Kabupaten Tanah Datar. Peraturan ini juga mencakup tentang biaya retribusi dan sanksi yang diberikan kepada oknum yang melanggar aturan tersebut. Kontribusi kelembagaan juga diperlukan untuk mengatur dan mengawasi proses pelaksanaan program-program kegiatan yang akan dan telah dilakukan.

\section{DAFTAR PUSTAKA}

Badan Pusat Statistik (BPS) Provinsi Sumatera Barat. 2014. Kabupaten Tanah Datar Dalam Angka. Padang: BPS

Kantor Lingkungan Hidup Kabupaten Tanah Datar.2012. Daftar Isian Non Fisik Kabupaten Tanah Datar

Kementrian Pekerjaan Umum Direktorat Jenderal Cipta Karya. 2014. Tata Cara Penyelenggaraan Umum Tempat Pengolahan Sampah (TPS) 3R Berbasis Masyarakat di Kawasan Permukiman. Jakarta

Peraturan Daerah Kabupaten Tanah Datar Nomor 2 tahun 2012. Rencana Tata Ruang Wilayah Kabupaten Tanah Datar 2011-2031

Peraturan Menteri Pekerjaan Umum Nomor 3/PRT/M/2013. Penyelenggaraan Prasarana dan Sarana Persampahan dalam Penanganan Sampah Rumah Tangga dan Sampah Sejenis Sampah Rumah Tangga

Peraturan Menteri Pekerjaan Umum Nomor 21/PRT/M/2006. Kebijakan dan Strategi Nasional Pengembangan Sistem Pengelolaan Persampahan (KSNP-SPP)

SNI 19-2454-2002. Tata Cara Teknik Operasional Pengelolaan Sampah Perkotaan.

SNI 3242-2008. Pengelolaan Sampah di Pemukiman

Undang-Undang Republik Indonesia Nomor 18 Tahun 2008. Pengelolaan Persampahan

Zulva, Indriyani. 2013. Studi Timbulan dan Komposisi Sampah Domestik Kabupaten Tanah Datar. Padang. Tugas Akhir: Universitas Andalas 